\title{
Döviz Kurlarının Bankacılık Sektörünün Performansı Üzerindeki Etkisi: Türkiye Örneği (2007-2016)
}

\author{
The Effect of Exchange Rates on the Performance of the Banking Sector; \\ The Case of Turkey (2007-2016)
}

\section{Asef YELGHi' 1 [}

\section{öz}

Son dönemde yükselen ekonomiler arasında yer alan Türkiye'nin ekonomik büyümesinin yavaşladığı ve para biriminin aşırı değer kaybettiği görülmektedir. Bankacılık sektörünün döviz kurlarındaki oynaklığa karşı duyarlıı̆̆ının yüksek olması, sektör performansını ve faaliyetlerini etkilemektedir. Kur ve bankacılık krizleri ile ilişkili yapılan analizlerde, kur dalgalanmaları ile bankacılık krizleri arasındaki ilişkiye odaklanılmakta ama banka performansı üzerindeki etkiler göz ardı edilmektedir. Bu bakımdan kur hareketlerinin banka performansına etkileri önemli ve üzerinde az durulan bir araştırma konusu olmaktadır. Çalışmada Türkiye'de döviz kurundaki oynaklığın bankacılık sektörünün performansı üzerindeki etkisi incelenecektir. 2007-2016 yıllar arası aylık kur verileri ile net faiz marjı, aktif getirisi ve öz kaynak getirisi gibi bankacılık sistemi temelli verileri kapsayan bir örneklem analiz edilmiştir. Analizlerde Pesaran ve Shin (1999) ve Pesaran v.d. (2001) önerdiği ARDL modeli kullanılmıştır. Ulaşılan bulgular; kurlar ile bankacılık sisteminin performansı arasında uzun dönemli bir ilişki olmadığını göstermiştir. Kur artışlarının bankacılık sektörünün performansını etkilemediği belirlendiğinden, sektörün kur riskine karşı dayanıklı olduğu sonucuna varılmıştır. Türk bankacılık sektörünün vadeli işlem piyasasında yoğunlaşması, kur riskine duyarlııı̆ı olan işlemleri kısıtlayıcı düzenlemeler uygulanması ve Basel III standartlarına uyum sürecinin hızlandırılması ile daha sağlam bir altyapıya kavuşabilecektir.

Anahtar kelimeler: Döviz kurları, banka performansı, Finansal Kriz, Aktif getirisi (ROA), Öz kaynak getirisi (ROE), Net faiz marjı (NIM)

JEL Classification: G00, G15, G19

\section{ABSTRACT}

Turkey, an emerging market economy, has undergone a slowdown in the economic growth and experienced an excessive currency depreciation

\begin{abstract}
*Bu çalışma Marmara Üniversitesi Bankacılık ve Sigortacılık Enstitüsü Bankacılık Doktora Programında Prof. Dr. K. Batu Tunay danışmanlığında yürütülen doktora tezimden üretilmiştir.
\end{abstract}

${ }^{1}$ Marmara Üniversitesi, Bankacılık Bölümü, İstanbul, Türkiye

ORCID: A.Y. 0000-0003-0683-7218

\section{Sorumlu yazar/Corresponding author:} Asef YELGHi,

Marmara Üniversitesi, Bankacılık Bölümü, İstanbul, Türkiye

E-posta/E-mail: Asefyelghi1365@gmail.com

Başvuru/Submitted: 03.11.2019

Revizyon Talebi/Revision Requested: 27.12.2019

Son Revizyon/Last Revision Received:

11.01.2020

Kabul/Accepted: 15.01.2020

Atıf/Citation: Yelghi, A. (2020). Döviz kurlarının bankacılık sektörünün performansı üzerindeki etkisi:Türkiye örneği (2007-2016). Iktisat Politikası Araştırmaları Dergisi - Journal of Economic Policy Researches, 7(2), 69-87

https://doi.org/10.26650/JEPR641975 
during recent years. High sensitivity to exchange rate leads to volatility in the banking sector and affects the monetary system and the banking activities. The analyses of the exchange rate and the banking crises are mostly focused on the relationship between these two, and neglect the impact on the banks' performance, while the exchange rate fluctuations are highly influential on the banks' performance. The present study is an attempt to fill this gap in the analyses. A sample including monthly exchange rate data between 2007 to 2016 and banking system data such as net interest margin, return on assets, and return on equity are analyzed. In the analysis, Pesaran and Shin (1999) and Pesaran et al. (2001) proposed the ARDL model to be used. The findings showed that there is no long-term relationship between exchange rates and the performance of the banking system. Thus, it is concluded that the sector is resistant to exchange rates. The Turkish banking sector will be able to attain a more robust infrastructure by concentrating in the futures market, implementing restrictive regulations on transactions sensitive to exchange rate risk and accelerating the compliance process with the Basel III standards.

Keywords: Exchange rates, bank performance, Financial Crisis, Return on assets (ROA), Return on equity (ROE), Net interest margin (NIM)

Jel Code: G00, G15, G19

\section{EXTENDED ABSTRACT}

Turkey's economy has recently undergone several major financial crises among which the 2000-2001 crisis seriously hit the banking sector through exchange rate fluctuations. Exchange rate shocks have become a source of risk for the banking sector. After the crisis, many banks were liquidated through the TMSF (Savings Deposit Insurance Fund), and strict supervision and surveillance measures were implemented; as a result, the sector recovered from the shock. Due to the uncompromising maintenance of these measures, the sector was not affected by the Global Financial Crisis in 2008, and proved itself to be one of the most robust banking systems among its counterparts within the framework of the Basel criteria. However, the growth of foreign capital share in the sector during the recent years and the increase of syndicated loans and foreign currency deposit accounts led to a rise in foreign exchange liabilities of Turkish banks, and hence, the vulnerability of the sector to sudden increases in exchange rates.

Major emerging economies such as Turkey have a rapid growth. However, in many of these countries, the national savings level is not sufficient to support the growth process and the savings deficit covered by foreign funds. When these funds are short-term and speculative, then, there is a problem regarding the sensitivity to exchange rate shocks.

The increase in the share of foreign capital in the Turkish banking sector is seen during the recent years. The increase in the foreign exchange liabilities of banks is due to syndicated loans and high foreign exchange deposit accounts making the sector vulnerable to sudden increases in exchange rates. It was observed that excessive volatility as well as sudden and large increases in foreign exchange rates pose a risk for banks. The findings of the studies reviewed in the literature indicate that this situation adversely affects the performance of the banking sector. 
In the analyses carried out on the exchange rate and the banking crises, which are called "twin crises" due to their relation and succession, the relationship between exchange rate fluctuations and the banking crises is ignored, and the effects on the performance of the banking sector are ignored. In other words, the effects of exchange rate fluctuations on the banking sector performance is an important but neglected research topic.

This study has two objectives: first, to examine the effects of the movements in exchange rates on the performance of the Turkish banking sector using the ARDL model for the time period of 2007 to 2016; second, to make suggestions for the improvement of the banking sector performance. Apart from the exchange rates, other factors affecting the banking sector performance have not been considered in the study.

This paper consists of three parts. In the first part, the factors affecting the banking sector performance are reviewed within the framework of the literature review. The examined studies were conducted on developed and developing countries. In the second part, there are evaluations regarding the general outlook of the Turkish banking sector. In the third part, the relationship between the fluctuations in the exchange rate and the performance of the banking sector is investigated with the aid of an econometric model. In the econometric analysis, the course of the banking sector in the face of rising exchange rates is traced and an answer is sought for the question of whether there is a long-term relationship between the exchange rate fluctuations and the banking sector performance.

In the literature, indicators such as return on assets (ROA) and return on equity (ROE) are used to measure and evaluate profitability-based bank performance, and analyze the market structure. Studies on profitability-based performance in developed countries have increased since the late 1970s. In the first studies, like Short's (1979), the relations between profitability and concentration were discussed. In other important studies, including Demirgüç-Knut and Huizinga (1999), Goddard et al. (2004), Athanasoglouv.d. (2006) and Dietrich and Wanzenried (2010), the focus was on the effects of internal and external factors on the profit or interest margin performance.

A peer integration analysis was conducted to investigate the long-term relationship between exchange rate fluctuations and the banking sector performance. As the analysis technique, the Peseranv.d. (2001), ARDL model developed by Pesaran and Shin (1999) was used. In this study, ROA, ROE and NIM variables were used as dependent variables, and Dollar and Euro exchange rates were used as independent variables.

The monthly data of 2007 to 2018 used in the analysis are derived from the official websites of the Banks Association of Turkey and the Central Bank. According to the analysis results, the Turkish banks' profitibility performance was not affected by exchange rate 
fluctuations, and it could be stated that the Turkish banking system is resistant to the exchange rate shocks.

There are many methods to minimize the exchange rate risk. Many of these methods are available in the futures market. Therefore, the development of the futures market is important in terms of making the banking sector resistant to the exchange rate risk. For this purpose, the infrastructure of the sector should be strengthened by fully complying with the regulations restricting foreign exchange risk sensitive transactions, establishing and following policies that encourage banks to share their experiences in this matter, and observing international standards and criteria. 


\section{Giriş}

Türkiye ekonomisi, yakın geçmişte birçok finansal kriz yaşamıştır. 2000-2001 krizinde ise bankacılık sektörü büyük zarar görmüştür. Bu krizlerde, döviz kurlarındaki hareketlerin de önemli etkileri olmuştur. Döviz kuru şokları, bankacılık sektörü için risk kaynağı haline gelmiştir. Krizden sonra çok sayıda banka Tasarruf Mevduatı Sigorta Fonu (TMSF) kanalıyla tasfiye edilmiş ve sıkı denetim ve gözetim tedbirleri uygulamaya konulmuştur. Neticede, sektör toparlanmıştır. Mevcut önlemlerin tavizsiz olarak sürdürülmesi nedeniyle sektör 2008'deki Küresel Finansal Kriz 'den fazla etkilenmemiş ve Basel kriterleri çerçevesinde benzerleri içinde en sağlam bankacılık sistemlerinden birisi olarak gösterilmiştir. Bununla beraber, son yıllarda sektörde yabancı sermayenin payının arttığı, sendikasyon kredilerinin ve döviz tevdiat hesaplarının yükseldiği gözlenmiştir. Bankaların döviz yükümlülüklerinde artışa yol açan bu gelişmeler, sektörü döviz kurlarındaki ani yükselişlere karşı kırılgan hale getirmiştir. Döviz kurlarındaki ani ve büyük artışlar kadar aşırı oynaklıkların da bankalar açısından risk oluşturduğu görülmüştür. Literatürdeki çalışmaların bulguları da bu durumun bankacılık sektörünün performansını olumsuz yönde etkilediği şeklindedir. Ne var ki, bu husus performansa dair çalışmalarda dolaylı olarak ele alınmaktadır. Zira döviz kuru ve bankacılık krizlerinin ilişkili ve ardıl olmalarına atfen "ikiz kriz" betimlemesi çerçevesinde yapılan analizlerde, kur dalgalanmaları ile bankacılık krizleri arasındaki ilişkiye odaklanılmakta ve bankacılık sektörünün performansı üzerindeki etkiler göz ardı edilmektedir. Bu bakımdan kur hareketlerinin bankacılık sektörü performansına etkileri önemli ancak üzerinde az durulan bir araştırma konusu olmaktadir.

$\mathrm{Bu}$ çalışmanın iki amacı vardır. Birincisi, döviz kurlarındaki hareketlerin Türk bankacılık sektörünün performansı üzerindeki etkilerini 2007-2016 dönemi için ARDL modeli kullanarak incelemek; ikincisi de bankacılık sektörünün performansını iyileştirmek için önerilerde bulunmaktır. Döviz kurları dışında bankacılık sektörü performansını etkileyen diğer faktörler çalışmanın kapsamına alınmayacaktır. Makale, üç bölümden oluşmaktadır. Birinci bölümde, literatür taraması çerçevesinde bankacılık sektörü performansını etkileyen faktörler ile, bu konuda gelişmiş ve gelişmekte olan ülkeler için yapılan çalışmalar incelenmektedir. İkinci bölümde, Türk bankacılık sektörünün genel görünümüne ilişkin değerlendirmeler yer almaktadır. Üçüncü bölümde, döviz kurundaki hareketler ile bankacılık sektörünün performansı arasındaki ilişki ekonometrik bir model yardımıyla araştırılmaktadır. Ekonometrik analizde, döviz kurlarının yükselmesi ve aşırı dalgalanması karşısında bankacılık sektörünün nasıl bir seyir izlediği; kur hareketleri ile performans arasında uzun dönemli bir ilişki olup olmadığı sorusuna yanıt aranmaktadır. 


\section{Literatür Taraması}

Bankacılık sektörü performansı birkaç boyutta değerlendirilmektedir. İlk boyut iç etkenler olarak tanımlanabilir. İç etkenler; büyüklük, kapitalizasyon, verimlilik, mülkiyet yapısı, risk ve yönetimi olarak sıralanabilir. İkinci boyut makro finansal değişkenler olarak nitelendirilebilir ve piyasa yoğunluğu, finansal piyasalarda vade yapısı gibi değişkenleri kapsar. Bir başka boyut da döviz kuru, enflasyon, faiz, istihdam, döngüsel hareketler gibi makroekonomik değişkenlerdir. Short'a (1979) göre her bankanın karlılığını etkileyen faktör farklıdır. Bankanın kamu mülkiyetinde olması ile özel sektörün mülkiyetinde olması durumunda elde ettiği kar arasında farklılık olmaktadır. Bankanın karlılığını etkileyen diğer bir potansiyel değişken kaldıraç oranın artması ile karlılığın yükselmesidir.

Banka başarısızlıklarını ve birleşmelerini tahmin etmek için kullanılan istatistiksel analizlerde bir karlılık ölçütünün gerekli olduğu ifade edilmektedir (Gilbert ve Wheelock, 2007; Christian v.d. 2008). Bankanın karlılığını ve performansını etkileyen birçok faktör vardır. Ancak, literatürde aktif getirisi (ROA), öz sermaye getirisi (ROE) gibi göstergeler, karlılığa dayalı banka performansını ölçmek, değerlendirmek ve pazarın yapısını analiz etmek için kullanılmaktadır. Banka performansı bankaya, finansal sisteme ve ekonominin geneline dair birçok faktörden etkilenmektedir. Küreselleşme, bu faktörlerin artmasına ve/ veya bazılarının daha çok önem kazanmasına yol açmıştır.

Ayrıca, net faiz marjı oranının da (NIM) performans göstergesi olarak birçok çalışmada kullanıldığı görülmektedir. Athanasoglou vd. (2006), Egesa (2010), Flamini vd. (2009), Xiaoqing (Maggie) Fu and Hefferman (2009) banka performansı değerlendirmelerinde aktif getirisi ve öz kaynak getirisi değişkenlerini kullanmışlardır. Brissimis vd. (2008), Saunders ve Schumacher (2000) ve Maudos ve Guevara (2004) ise net faiz marjını da kullanmışlardır.

Net kar / aktif toplam oranı ile aktif getirisi elde edilmektedir. Aktif getirisi işletmenin ya da bankanın varlıklarının kar yaratmada ne kadar etkin olduğunu göstermektedir. Net kar / öz kaynak oranı ile öz kaynak getirisi elde edilmektedir. Banka sahiplerinin yatırdıkları sermayenin ne kadar verimli kullanıldığını göstermektedir. Net faiz Geliri / Ortalama Getiri Aktifler oranı net faiz marjı oranı olarak tanımlanmaktadır. Net faiz marjı, bankanın karının ne kadarının faiz gelirlerinden oluştuğunu göstermektedir. Buna göre faizlerinin dalgalanması ile bankanın karlılığı da etkilemektedir.

\subsection{Gelişmiş Ülkelerdeki Çalışmalar}

Gelişmiş ülkelerde karlılığa dayalı performans üzerine çalışmalar 1970’lerin sonlarından itibaren artmıştır. İlk çalışmalarda karlılık ile yoğunlaşma arasındaki ilişkiler ele alınmıştır. Örneğin; Short (1979) Kanada, Batı Avrupa ve Japonya'da60 bankanın 1972-1974 yıllar 
arası yıllık veriler üzerinden karlılık oranları ile piyasa yoğunluğu arasındaki ilişkiyi incelemiştir. Çalışma sonucunda, banka karlılık oranları ve piyasa yoğunluğu arasındaki ilişkinin anlamlı ve güçlü olduğu tespit edilmiştir. Smirlock (1985), pazar payı ve kârlılık arasında pozitif bir ilişki olduğunu saptamıştır. Piyasa yoğunluğu ile kar arasında doğrudan önemli bir ilişki bulmamıştır.

Molyneux ve Thornton (1992), Avrupa bankalarının performansını incelemiştir. Çalışmada 18 ülkenin 1986-1989 dönemine ait yıllık veriler ile kesitsel denklemlerden yararlanılmıştır. Analiz edilen modelde, kârlılığın belirleyicilerinin bankanın büyüklügüü, çeşitlilik, risk ve mülkiyet tipinin yanı sıra dinamik etkileri de kapsadığı görülmüştür. Çalışma, bankanın büyüklüğü ve karlılık arasında nispeten zayıf bir ilişki olduğunu ortaya koymuştur. Bir başka bulguları da İngiltere haricindeki ülkelerde, bilanço dışı banka portföyleri ile banka performansı arasında nötr ve/veya negatif ilişkiler olduğudur.

Başka bir çalışmada, Goddard v.d. (2004), Avrupa ülkelerinin bankaların performansları ile bankacılık sisteminin aktiflerinin vadeleri, büyüklükleri ve gelişme düzeyleri arasındaki ilişkiyi incelemişlerdir. Bankacılık sektörü büyüklüğü ile banka performansı arasında zayıf bir ilişki olduğu görülmüştür. Chamberlin v.d. (1996), Bracker v.d. (2009), He v.d. (2014), Kemisola'nın (2016) çalışmaları, doğrudan kurların performansa etkilerini ele aldığından literatürdeki diğer çalışmalardan farklılaşmaktadır. Chamberlin v.d. (1996), ABD ve Japon bankalarının döviz kuru riskine ne oranda maruz kaldıklarını incelemiştir. Çalışmada kesit analizi yöntemi ile ABD bankalarının hisse senedi getirileri ile döviz kuru arasında anlamlı bir ilişki olduğu bulunmuş, Japon bankalarında ise böyle bir ilişkiye rastlanmamıştır.

Demirgüç-Knut ve Huizinga (1999), Goddard v.d. (2004), Athanasoglou v.d. (2006) ve Dietrich ve Wanzenried (2010); bankalardaki iç ve dış faktörlerin kar veya faiz marjı performansı üzerindeki etkilerine odaklanmaktadır. Athanasoglou v.d. (2006), 1992-2002 yılları arası Güney Doğu Avrupa ülkelerinde bankacılık sektörünün karlılık davranışlarını incelemiştir. Analizin sonuçları, likidite hariç, bankaya özgü tüm belirleyici faktörlerin beklenen şekilde banka kârlılığını önemli ölçüde etkilediğini göstermektedir. Bracker v.d. (2009), He v.d. (2014) gibi bazı ampirik çalışmalar, küresel ölçekte faaliyet gösteren bankalarda kur hareketleri ile banka getirileri arasında güçlü ilişkiler olduğunu göstermektedir. Bracker v.d. (2009), banka hisse senedi getirisi ile risk faktörleri arasındaki ilişkiyi incelemiştir. Bu çalışmada kur riski ile hisse senedi getirisi arasında anlamlı bir ilişki olduğu ortaya çıkmıştır. He v.d. (2014), 1978-2008 yılları arasında ABD’de 22 ticari bankanın performansı ile döviz kuru arasındaki ilişkiyi regresyon modeli ile incelemiştir. Çalışmanın sonucunda, doların uluslararası piyasadaki, spesifik olarak Avrupa piyasasındaki ve Asya piyasasındaki değeri ile ABD ticari bankalarının getirileri arasında güçlü ilişkiler saptanmıştır. 


\subsection{Gelişmekte Olan Ülkelerdeki Çalışmalar}

Gelişmekte olan ülkelerde ise Wong ve Leong (2008), 14 ticari Çin bankası için döviz kuru ile bankacılık sektörü arasındaki ilişkinin incelemesinde klasik en küçük kareler yöntemini kullanmışlardır. Bulgular; banka büyüklügü ile döviz kuru riski arasında pozitif ilişki olduğu göstermiştir. Samadi v.d. (2012), operasyon riski ve sermaye yapısının bankacılık sektörünün karlılığı üzerindeki etkilerini araştırmıştır. Çalışma, İran'da 2006'dan 2010'a kadar aktif olan 17 ticari bankanın sermaye yapısı ile kârlılık arasındaki ilişkiyi test etmiştir. Bu değişkenler arasında pozitif bir ilişki olmasına rağmen, işletme riski ile sermaye yapısı arasında anlamlı bir ilişki olmadığı belirlenmiştir.

Almazari (2013), Suudi Arabistan'da sermaye yeterliliği ve karlılık arasındaki ilişkiyi incelemiştir. Borsaya kote olan 9 Suudi bankasının 2007-2011 dönemindeki mali tablolarından toplanan verilerle doğrusal regresyon tekniği kullanılarak yapılan analizde; sermaye yeterliliği, maliyet-gelir oranı ve banka büyüklügü ile karlılık arasında anlamlı ve güçlü ilişkiler olduğu ortaya çıkmıştır. Bu çalışmada, varlıkların getirisi ve öz kaynakların getirisi ile temsil edilen kârlılığın sermaye yeterliliği ile negatif bir ilişki içinde olduğu tespit edilmiştir. Suudi bankalarının maliyet-gelir oranı ile ölçülen verimliliğinin banka karlılığı ile negatif ilişkili olduğu görülmüştür.

Osuagwo (2014), Nijerya bankacılık sektörü aktif toplamının \%60'1nı oluşturan bankaları kapsayan çalışmasında, 1980-2010 yıllarına ait verilerle bir doğrusal regresyon modeli kullanarak yaptığı uygulama sonucunda, banka performans göstergesi olarak öz kaynak getirisi oranları ile net faiz marjının döviz kurlarından etkilendiğini fakat aktif getirisi oranlarının döviz kurlarından etkilenmediğini göstermiştir. Nouaili v.d. (2015), Tunus’ta bankacılık sektörü performansını etkileyen unsurları incelemiştir. Regresyon analizi sonucunda, banka kapitalizasyonu, özelleştirme ve fiyatlandırma ile banka performansı arasında pozitif ilişkiler olduğu saptanmıştır. Shamki v.d. (2016), 2005-2013 yılları arasında Ürdün ticari bankaları için sermaye oranının, büyüklüğün ve kredilerin, karlılık üzerindeki etkisini regresyon modeli kullanarak incelemişlerdir. Çalışmanın sonuçları, bankaların sermaye oranlarının, büyüklüklülerinin ve kredilerinin aktif getirileri üzerinde önemsiz etkileri olduğunu göstermiştir. Ancak, banka büyüklüğü hariç diğer değişkenlerin öz kaynak getirisini etkilemediği görülmüştür. Nagahisarchoghaei vd. (2018), 2011-2012 yılları arasında 242 şirketin verileri ile çoklu regresyon modeli kullanarak, döviz kurları ile şirket performansları arasında anlamlı bir ilişki olduğu sonucuna ulaşmışlardır.

\section{Türkiye'de Bankacılık Sektörünün Genel Görünümü}

1994 Meksika Krizi, 1997 Tayland, Kore, Endonezya Krizi, 2000 Arjantin Krizi’nin ortak özellikleri aşırı değerli döviz kuru sonucunda ortaya çıkan ekonomik daralmalar, döviz 
kuru riskinin kontrolü konusunu önemli hale getirmiştir (Kaya, 2018;842). Yükselen piyasa ekonomilerinden biri olan Türkiye'de, 1994 ve 2001 krizlerinde ulusal para aşırı değer kaybetmiştir. 2000 yılı Kasım ayından itibaren kamu bankalarının ve özel bankaların likidite açığı sorunu yaşaması, piyasada gerilim yaratmış ve mevcut IMF programını sürdürebilirliği tartışılmaya başlanmıştır. Diğer taraftan, küresel ölçekte döviz kurunun çıpa olarak kullanıldığı ve parasal genişlemenin döviz girişine bağlı olduğu programlara yönelik algılar da bozulmuştur (BDDK, 2010;21). 2000 krizinde, döviz kuru ve likidite baskısını hafifletmek üzere Stand-By anlaşması kapsamında Ek Rezerv kolaylığı kullanılması, finansal piyasalardaki dalgalanmaların giderilmesinde olumlu etki yaratmıştır. Ancak, kriz öncesine göre artan faizler, kamu bankalarının portföylerinde tuttukları yüksek miktardaki iç borçlanma senetleri nedeniyle bilançoların bozulmasına yol açmıştır (BDDK, 2010: 25). Çok sayıda banka mali durumlarının düzeltilemeyeceği anlaşıldığından, tasfiye edilmeleri için TMSF’ye devredilmiştir.

Kasım 2000'de ve Şubat 2001'de üst üste gelen krizler bankacılık sektörünü çok olumsuz etkilemiştir. 2001 krizinin temeli 1990'da kullanılan döviz kuru politikasına bağlanabilir (Kaplan, 2002: 1-6). 2001 krizi sonrasında döviz kurlarının aşırı dalgalanması sonucu ekonomide olumsuz gelişmeler yaşanmıştır. Buna göre sürünen sabit döviz kuru sisteminden (crowling peg regime) vazgeçilmiş ve dalgalı döviz kuru rejimi (floating exchange rate regime) uygulanmaya başlamıştır (Kaya, 2018: 843). Bu süreçte bankacılık sektöründe yeniden yapılandırmaya gidilmiştir. Çabalar başarılı olmuş, alınan önlemler sayesinde Türkiye 2007-2008 Küresel Krizinden en az olumsuz etkilenen ülkeler arasında yer almıştır. Son yıllarda, döviz kurlarının aşırı yükselmesi ve dalgalanması nedeniyle hem genel olarak ülke ekonomisinin hem de özelde bankacılık sektörünün kırılgan hale geldiği görülmektedir. Bankacılık sektörünün ciddi döviz yükümlülüklerinin olması ve bunlar içinde kısa vadeli yükümlülüklerin oranının yüksekliği dolayısıyla sektör döviz kuru şoklarına karşı çok duyarlıdır. Türk bankacılık sektörünün döviz pozisyonlarındaki dramatik gelişmeler bu hususu teyit etmektedir (Grafik 1).

\section{Grafik 1. Türkiye Bankacılık Sektörünün Yabancı Para Pozisyonu}

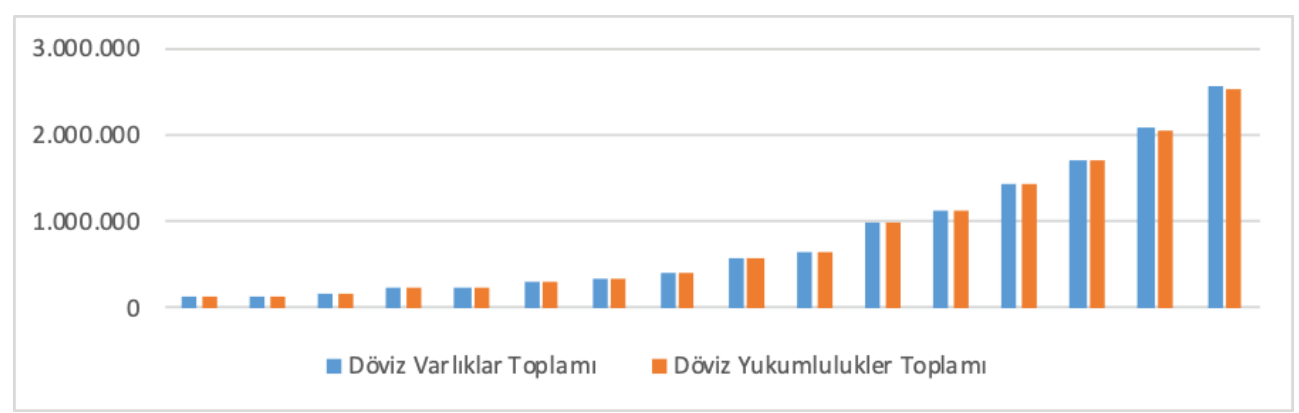

Kaynak: BDDK 
Türk bankacılık sektöründe döviz cinsinden toplam varlıklar ve toplam yükümlülüklerin hızlı bir artış gösterdiği görülmektedir. 2003 yılında döviz varlıkları yaklaşık 125 milyar TL, döviz yükümlülükleri de yaklaşık 125 milyar TL'dir. 2018 yılında ise, döviz varlıkları 2 trilyon TL olmuş, döviz yükümlülükleri de 2,5 trilyon TL'ye yükselmiştir. Türk bankacılık sektörü, 2008 Küresel Kriz öncesinde oldukça düşük seviyede bir yabancı para pozisyonuna sahipken, kriz sonrasında yabancı para pozisyonu çok hızlı yükselmiştir (Grafik 1).

\section{Grafik 2. Türkiye Bankacılık Sektörünün Kar / Zarar Durumu}

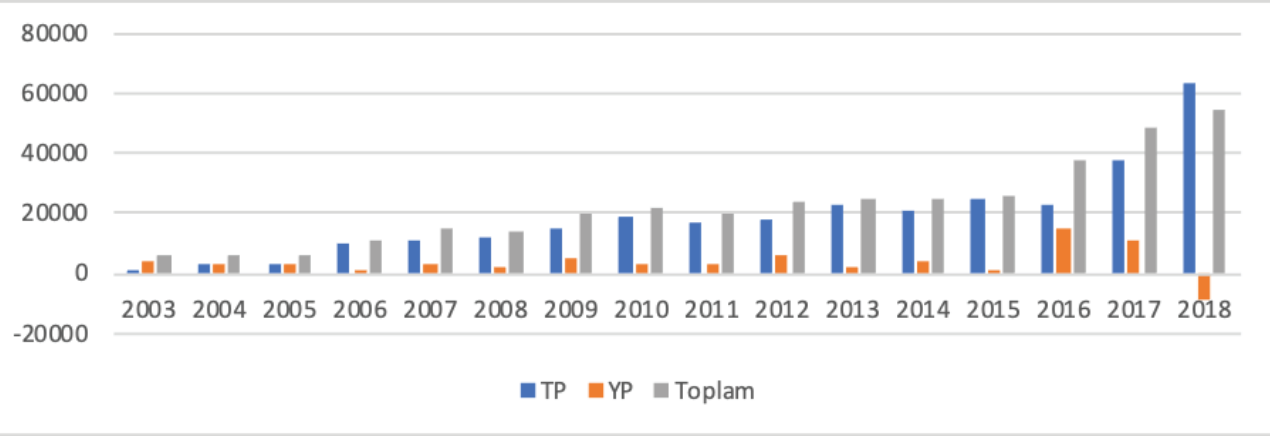

Kaynak: BDDK

Öte yandan, Türk bankacılık sektörünün toplam karının 2003 itibariyle yükseldiği görülmektedir (Grafik 2). Bankacılık sektörü 2003'de TL cinsinden yaklaşık 1.3 milyar TL ve yabanc1 para cincinden 4.2 milyar TL olmak üzere, toplam 5.5 milyar TL net kar elde etmiştir. 2018'de ise 62 milyar TL (TL cinsinden) ve -8 milyar TL (yabancı para cinsinden), toplam 54 milyar TL kar ettiği görülmüştür. Ancak, döviz cinsinden elde edilen karın istikrarsız seyir ettiği anlaşılmaktadır. İlk yıllarda yabancı para cinsinden elde edilen kar TL cinsinden elde edilen kara göre yüksek iken, son yıllarda düşüş yaşanmıştır. Bu da 20002001 krizleri sonrası yapılan reformlar sayesinde, bankacılık sektörünün 2008 Küresel Krizinden fazla etkilenmediğine işaret etmektedir. 2007 yılından sonra sektörün toplam net karı yükselmiştir (Grafik 2).

\section{Grafik 3. Dolar ve Euro Kurlarının Gelişimi}

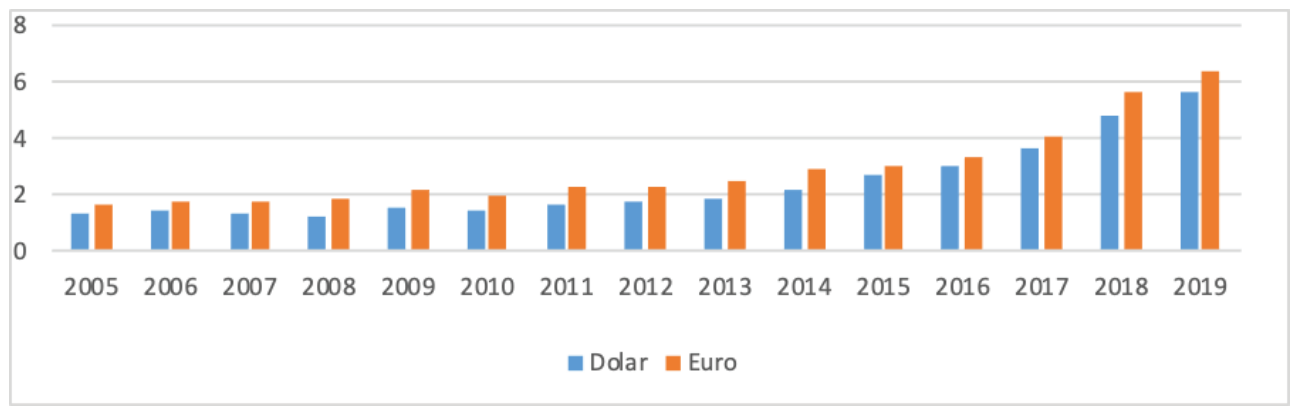

Kaynak: BDDK 
Bankacılık sisteminde ve ekonomide ağırlıklı olarak ABD Doları ve Euro işlem görmektedir. Grafik 3, bu kurlardaki gelişimi vermektedir. 2007-2008 Küresel Krizini takiben kurlarda istikrarlı bir artış olduğu gözlenmektedir. 2012 yılı sonrası dönemde ise kurlardaki artış hızlanmıştır.

Zeyneloğlu (2017), Türk bankacılık sektörü için Şubat 2000 ve Kasım - Aralık 2016 döneminde döviz kurlarındaki ani yükseliş ile bankacılık davranışı arasındaki ilişkiyi incelemiştir. Sonuçlar, 2000 yılında döviz kurlarındaki ani yükselişin bankacılık faaliyetleri üzerinde önemli rol oynadığı, 2016'de ise bu etkinin sınırlı kaldığ 1 yönünde olmuştur. Kılc1 (2019), takipteki krediler ile döviz kuru arasındaki ilişkiyi incelemiştir. Çalışmada, 2008/012008/12 dönemine ait aylık veriler ile Fourier ADL modeli kullanılmıştır. Sonuçlar, döviz kuru ile takipteki krediler arasında uzun dönem bir ilişki olduğunu ortaya koymuştur.

Gökçe ve Sarıtaş (2017), 39 özel sermayeli bankanın bilanço kalemleri ile dolar kuru arasındaki ilişkiyi araştırmışlardır. Bulguları, döviz kurlarındaki değişmelerin bankaların bilanço kalemlerinde değişime neden oluğu yönündedir. Buch ve Heinrich (1999), döviz kurundaki artış beklentisinin bankaların net karını düşürebileceğini, dış borçlanma güçlerini azaltabileceğini ve bankacılık krizine yol açabileceğini vurgulamışlardır. Bleaney vd. (2008) ise mudilerin bankadan paralarını çekerek yabancı paraya dönüştürmeleri durumunda hem bir döviz kuru krizinin hem de bankacılık krizinin ortaya çıkabileceğini belirtmişlerdir.

\section{Araştırma Yöntemi}

Bankacılık sektörü yapısı gereği döviz kurlarındaki oynaklıktan etkilenmekte ve bu nedenle de döviz kuru hareketleri ile bankacılık sektörü performansı arasındaki ilişkinin incelenmesi önem taşımaktadır. Bu bölümde, döviz kuru hareketleri ve bankacılık sektörü performansı arasındaki uzun dönemli ilişkinin araştırılması amacına yönelik olarak bir eş bütünleşme analizi yapılacaktır. Analiz tekniği olarak, Peseranv.d. (2001), Pesaran ve Shin (1999) tarafından geliştirilen ARDL modeli tercih edilmiştir. Literatürde genellikle banka performansı ölçütü olarak aktif getirisi (ROA), öz sermaye getirisi (ROE) ve net faiz marjının (NIM) kullanıldığı görülmektedir. Çalışmamızda da bu değişkenler benimsenmiştir. Dolar ve Euro kurları da bağımsız değişkenler olarak kullanılacaktır. Analizlerde, TCMB ve Türkiye Bankalar Birliğinin resmi internet sitelerinden derlenen 2007-2018 yıllarına ait aylık verilerden yararlanılmıştır. Tablo 1'de değişkenler bağımlı veya bağımsız olmalarına göre sıralanmıştır. Serilerinin mevsimsellikten arındırıldıktan sonra logaritmalarını alınmıştır. 
Tablo 1. Bağımlı ve Bağımsız Değişkenler

\begin{tabular}{cc}
\hline Bağımlı Değişken & Net Faiz Marjı (NIM) \\
Bağımlı Değişken & Varlıklar Getirisi (ROE) \\
Bağı̆ılı Değişken & Öz Kaynak Getirisi (ROA) \\
Bağımsız Değişken & Dolar \\
Bağımsız Değişken & Euro \\
\hline
\end{tabular}

ARDL modeli uygulamadan önce serilerinin durağan olup olmadığı incelenmiştir. Bununla beraber ARDL modelinin uygulaması için serilerinin aynı seviyede durağan olması bir ön koşul olarak aranmamaktadır. Serilerinin durağan olup olmadığını araştırmak için Genişletilmiş Dickey-Fuller (ADF) ve Philinps-Perron (PP) testleri uygulanmıştır (Tablo 2).

Tablo 2.Birim Kök Testi

\begin{tabular}{|c|c|c|c|c|c|c|}
\hline \multirow[t]{2}{*}{ DEĞİŞKEN } & \multicolumn{3}{|c|}{ Genişletilmiş Dickey-Fuller (ADF) } & \multicolumn{3}{|c|}{ Philips-Perron(PP) } \\
\hline & SABITTLI & $\begin{array}{l}\text { SABİTLİ- } \\
\text { TRENDLI }\end{array}$ & $\begin{array}{l}\text { SABITSIZ- } \\
\text { TRENDSIZ }\end{array}$ & SABİTLİ & $\begin{array}{l}\text { SABITLLI- } \\
\text { TRENDLII }\end{array}$ & $\begin{array}{l}\text { SABITSIZ- } \\
\text { TRENDSIZ }\end{array}$ \\
\hline IDolar & 0.9989 & 0.6876 & 0.9994 & 0.9968 & 0.6672 & 0.9986 \\
\hline IEuro & 0.9993 & 0.9486 & 0.9995 & 0.9973 & 0.9115 & 0.9990 \\
\hline INim & $0.0001^{* * *}$ & $0.0000^{* * *}$ & $0.0999^{*}$ & $0.0000^{* * *}$ & $0.0000^{* * *}$ & $0.0086^{* *}$ \\
\hline 1Roa & 0.1047 & $0.0003^{* * *}$ & $0.0344 * *$ & $0.0000^{* * *}$ & $0.0000^{* * *}$ & $0.0000^{* * *}$ \\
\hline IRoe & $0.0308 * *$ & $0.0091 * *$ & 0.4306 & $0.0000 * * *$ & $0.0000 * * *$ & 0.5066 \\
\hline$\Delta$ Dolar & $0.0000^{* * *}$ & $0.0000^{* * *}$ & $0.0000^{* * *}$ & $0.0000^{* * *}$ & $0.0000^{* * *}$ & $0.0000^{* * *}$ \\
\hline$\Delta$ Euro & $0.0000 * * *$ & $0.0000^{* * *}$ & $0.0000^{* * *}$ & $0.0000^{* * *}$ & $0.0000^{* * *}$ & $0.0000^{* * *}$ \\
\hline$\Delta \mathbf{R o e}$ & $0.0000 * * *$ & $0.0000 * * *$ & $0.0000 * * *$ & $0.0001 * * *$ & $0.0001 * * *$ & $0.0000 * * *$ \\
\hline
\end{tabular}

Not: ${ }^{*}, * *$ ve ${ }^{* * *}$ sirasıly $\% 90, \% 95$ ve $\% 99$ güven aralığını temsil etmektedir.

Tablo 2'den, serilerin aynı seviyede durağan olmadıkları görülmektedir. Net faiz marjı ve aktiflerin getirisi değişkenleri düzey hallerinde durağanken; Dolar ve Euro kurları ile ROE değişkenlerinin birinci farklarının durağan oldukları görülmektedir. Dolayısıyla, böyle bir örneklem için panel ARDL modeli en uygun analiz seçeneğidir.

Genelleştirilmiş ARDL (p,q) modeli aşağıdaki denklemle ifade edilebilir:

$$
Y_{t}=\gamma_{0 i}+\sum_{i=1}^{p} \delta_{i} Y_{t-i}+\sum_{i=0}^{q} \beta_{i}^{\prime} X_{t-i}+\varepsilon_{i t}
$$

(1) numaralı eşitlikte Yt bağımlı değişkenler vektörü, Xt bağımsız değişkenler matrisidir. yi kesite özel model sabitini, cit hata terimini göstermektedir. p bağımlı değişkenler için q ise bağımsız değişkenler için optimum gecikme sayısını ifade etmektedir.

(1) numaralı eşitlikten hareketle analizlerde kullanacağımız ilk ARDL modeli aşağıdaki gibi ifade edilebilir: 


$$
\begin{aligned}
& \Delta \text { Nim }_{t}=a+\sum_{i: 1}^{p} \delta_{i} \text { Vnim }_{t-i}+\sum_{\mathrm{I}=1}^{q_{1}} \beta_{i, 1} \text { Vdolar }_{t-i} \\
& +\sum_{i=1}^{q_{2}} \beta_{i, 2} \text { Veuro }_{t-i}+a_{1} \text { nim }_{t-1}+a_{2} \text { Dolar }_{t-1}+a_{3} \text { Euro }_{t-1}
\end{aligned}
$$

(2) numaralı eşitlikte NİM bağımlı değişkendir. Bu eşitlikten hareketle yapılan eşbütünleşme tahminleri Tablo 3'de sunulmuştur.

Tablo 3. Döviz Kurları ile Net Faiz Marjı Eş bütünleşme Test Sonuçları

\begin{tabular}{ccccc}
\hline Değişkenler & Katsayı & Std. Hata & t Testi & p Değeri \\
\hline C & 0.362362 & 0.163420 & 2.217 .370 & 0.0282 \\
LogNim(-1) & -0.552922 & 0.106389 & -5.197 .166 & $0.0000 * * *$ \\
LogDolar & -0.189614 & 0.290692 & -0.652287 & 0.5153 \\
LogEuro & 0.101208 & 0.356165 & 0.284161 & 0.7767 \\
LLog Nim(-1) & -0.372605 & 0.079763 & -4.671 .387 & 0.0000 \\
LogDolar & -0.342932 & 0.520020 & -0.659459 & 0.5107 \\
LogEuro & 0.183043 & 0.642647 & 0.284826 & 0.7762 \\
C & $0.655359 * * *$ & 0.267397 & 2.450 .885 & 0.0155 \\
F Testi & & & & \\
Anlamlilik & $6,77 * * *$ & & \\
$10 \%$ & $\mathrm{I}(0)$ & $\mathrm{I}(1)$ & & \\
$5 \%$ & 2,63 & 3,35 & & \\
\% 2.5 & 3,1 & 3,87 & & \\
$1 \%$ & 3,55 & 4,38 & & \\
\hline
\end{tabular}

Not: $*, * *$ ve $* * *$ sirasıyla $\% 90, \% 95$ ve $\% 99$ güven aralığını temsil etmektedir.

Tablo 3’ten, modelin hata terimi (-0.55), -2 ve sıfır arasında bir değer aldığı için istatiksel olarak anlamlı olduğu söylenebilir. Net faiz marjı ile döviz kurlarına uygulanan ARDL sınır testinin sonuçları görülmektedir. Buna göre F testi 6,77 değeri ile 99\% anlamlılık düzeyinde anlamlı bulunmuştur. Sunulan sonuçlar Dolar ve Euro kurları ile net faiz marjı arasında uzun dönemde herhangi bir ilişki bulunmadığını göstermektedir. Grafik 4'de sunulan kümülatif toplam (cusum) grafiğine göre, Dolar ve Euro ile net faiz oranı eşbütünleşiktir, ancak uzun dönemde aralarında bir ilişki yoktur.

\section{Grafik 4. Net Faiz Marjı ile Döviz Kurları Cusum Grafiği}

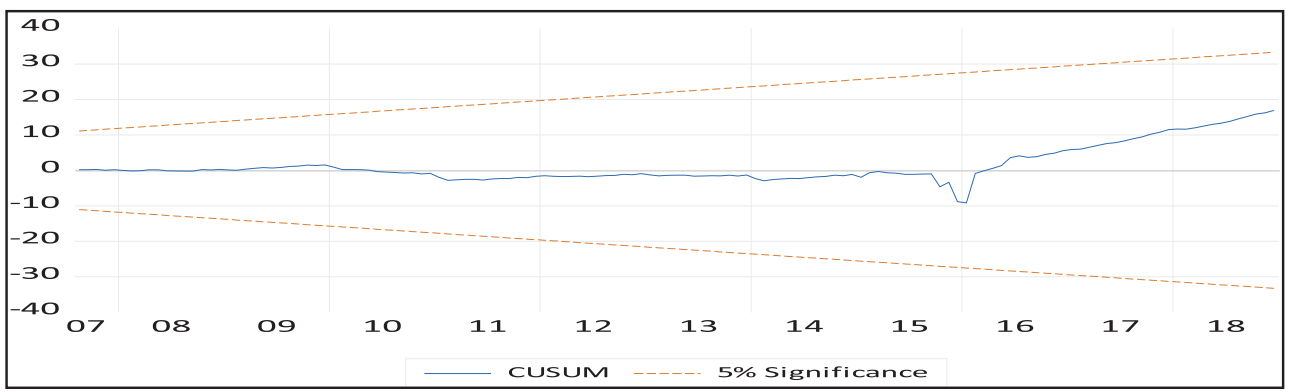


Aşağıda aktif karlılığının bağımlı değişken olarak dikkate alındığı denklem sunulmuştur:

$$
\begin{aligned}
& \Delta \text { roa }_{t}=a+\sum_{i: 1}^{p} \delta_{i} \text { Vroa }_{t-i}+\sum_{\mathrm{i}=1}^{q_{1}} \beta_{i, 1} \text { Vdolar }_{t-i} \\
& \quad+\sum_{i=1}^{q_{2}} \beta_{i, 2} \text { Veuro }_{t-i}+a_{1} \text { roa }_{t-1}+a_{2 \text { Dolar }_{t-1}}+a_{3} \text { Euro }_{t-1}
\end{aligned}
$$

Tablo 4. Döviz Kurları ile Varlıklar Getirisi Eş bütünleşme Test Sonuçları

\begin{tabular}{ccccc}
\hline Değişken & Katsayı & Std. Hata & t-Statistik & P-Değeri \\
\hline C & 0.138176 & 0.158654 & 0.870925 & 0.3854 \\
LogRoa(-1)* & $-0.217009 * *$ & 0.097887 & -2.216 .930 & 0.0283 \\
LogDolar & 0.128975 & 0.338743 & 0.380745 & 0.7040 \\
LogEuro & -0.282734 & 0.395017 & -0.715752 & 0.4754 \\
$\Delta($ LogRoa(-1)) & $-0.545075^{* * *}$ & 0.113450 & -4.804 .554 & 0.0000 \\
$\Delta($ LogRoa(-2)) & $-0.333599 * * *$ & 0.109959 & -3.033 .848 & 0.0029 \\
D(LogRoa(-3)) & $-0.150677 *$ & 0.087344 & -1.725 .086 & 0.0868 \\
LogDolar & 0.594329 & 1.698 .362 & 0.349942 & 0.7269 \\
LogEuro & -1.302 .869 & 2.082 .856 & -0.625520 & 0.5327 \\
C & 0.636729 & 0.830447 & 0.766731 & 0.4446 \\
F Testi & & & & \\
Anlamlilik & $\mathrm{I}(0)$ & $\mathrm{I}(1)$ & & \\
$10 \%$ & 2,63 & 3,35 & & \\
$5 \%$ & 3,1 & 3,87 & & \\
02.5 & 3,55 & 4,38 & 5 & \\
\end{tabular}

Not: ${ }^{*}, * *$ ve ${ }^{* * *}$ sirasılyla $\% 90, \% 95$ ve $\% 99$ güven aralığını temsil etmektedir.

(2) numaralı eşitliğin tahmin edilmesi sonucunda, bankaların aktif getirisi ile Euro ve dolar kurları arasındaki ilişki test edilmiş ve sonuçlar Tablo 4'de sunulmuştur. Tablo 4'e göre, hata terimi (-0.21), -2 ve sıfır arasında bir değer aldığı için istatiksel olarak anlamlı ve eş bütünleşiktir. Sunulan testi Peseran kritik değerlerine göre anlamsızdır. Dolar ve Euro kurları ile banka aktif getirisi arasında uzun dönemde her hangi bir ilişki olmadığı görülmektedir. Grafik 5'deki cusum grafiğine bakıldığında model istikrarlı ve güvenilirdir. Sonuç olarak, Dolar ve Euro kurları ile ROA arasında uzun dönem ilişki olmadığı ortaya çıkmıştır.

\section{Grafik 5. Döviz Kurları ile Varlıklar Getirisi Cusum Grafiği}

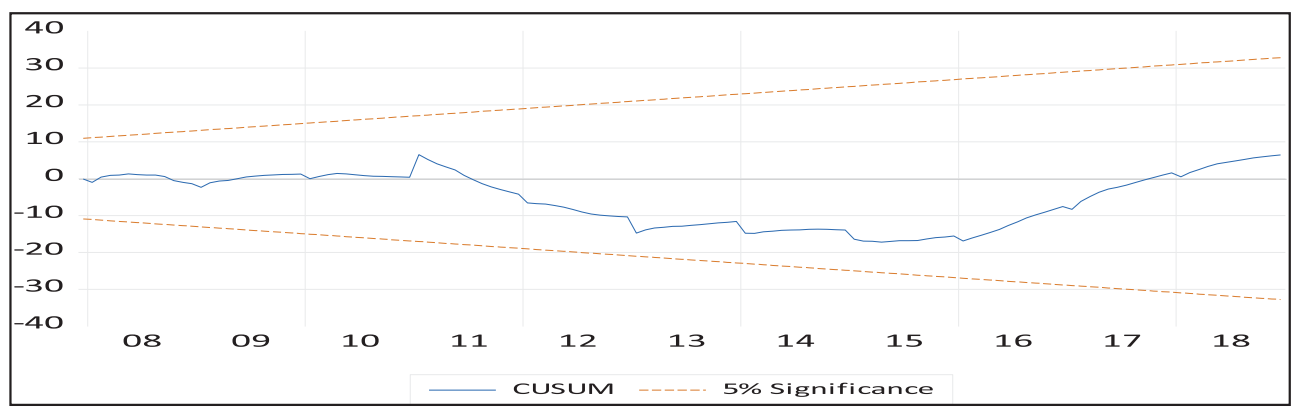


Aşağıda öz kaynak karlılığının bağımlı değişken olarak dikkate alındığı denklem sunulmuştur. Bu denklemden hareketle yapılan ARDL tahmini ise Tablo 5'de görülebilir.

$$
\begin{aligned}
\Delta \text { roe }_{t} & =a+\sum_{i: 1}^{p} \delta_{i} \text { Vroe }_{t-i}+\sum_{\mathrm{i}=1}^{q_{1}} \beta_{i, 1} \text { Vdolar }_{t-i} \\
& +\sum_{i=1}^{q_{2}} \beta_{i, 2} \text { Veuro }_{t-i}+a_{1} \text { roe }_{t-1}+a_{2 \text { Dolar }_{t-1}}+a_{3} \text { Euro }_{t-1}
\end{aligned}
$$

\begin{tabular}{|c|c|c|c|c|}
\hline Değişken & Katsayı & Std. Hata & t-Statistik & P-değeri \\
\hline $\mathrm{C}$ & $0.701958 * * *$ & 0.254928 & 2.753 .556 & 0.0067 \\
\hline LogRoe(-1) & $-0.269282 * *$ & 0.112606 & -2.391 .359 & 0.0182 \\
\hline LogDolar & 0.158048 & 0.365848 & 0.432003 & 0.6664 \\
\hline LogEuro & -0.292807 & 0.429936 & -0.681047 & 0.4970 \\
\hline$\Delta(\operatorname{LogRoe}(-1))$ & $-0.534225 * * *$ & 0.121404 & -4.400 .378 & 0.0000 \\
\hline$\Delta(\log \operatorname{Roe}(-2))$ & $-0.345477 * * *$ & 0.112892 & -3.060 .256 & 0.0027 \\
\hline$\Delta(\log \operatorname{Roe}(-3))$ & -0.126825 & 0.087545 & -1.448 .680 & 0.1498 \\
\hline LogDolar & 0.586922 & 1.491 .262 & 0.393574 & 0.6945 \\
\hline LogEuro & -1.087 .360 & 1.817 .911 & -0.598137 & 0.5508 \\
\hline $\mathrm{C}$ & 2.606 .773 & 0.720671 & 3.617 .148 & 0.0004 \\
\hline F-statistiği & \multicolumn{2}{|c|}{2,26} & & \\
\hline Anlamlılık & $\mathrm{I}(0)$ & $\mathrm{I}(1)$ & & \\
\hline $10 \%$ & 2,63 & 3,35 & & \\
\hline $5 \%$ & 3,1 & 3,87 & & \\
\hline$\% 2.5$ & 3,55 & 4,38 & & \\
\hline $1 \%$ & 4,13 & 5 & & \\
\hline
\end{tabular}

Tablo 5. Döviz Kurları ile Öz sermaye Getirisi Eş bütünleşme Tablosu

Tablo 5'de sunulan bulgular incelendiğinde, hata terimi (-0.26), -2 ve sifır arasında bir değer aldığı için statiksel olarak anlamlıdır. Verilen sınır testi sonuçları Peseran kritik tablosuna göre anlamsız olduğunu göstermektedir. Bulgular, dolar ve Euro kurları ile öz sermaye getirisinin uzun dönemde herhangi bir ilişki içinde olmadığını göstermektedir. Grafik 6'da sunulan Cusum grafiğine göre model istikrarlı ve güvenilir. Sonuç olarak hem eşbütünleşik değildir ve hem de uzun dönemde aralarında bir ilişki yoktur.

\section{Grafik 6:Döviz Kurları ile Öz sermaye Getirisi Cusum Grafiği}

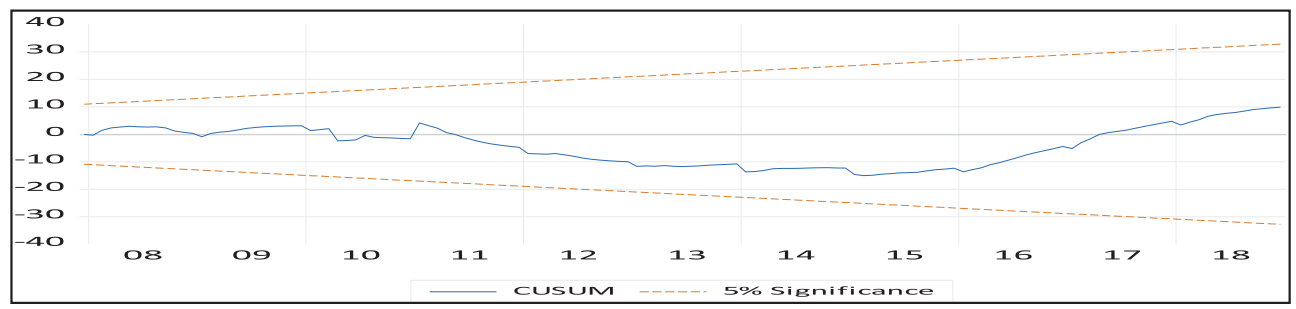




\section{Politika Önerileri}

Son dönemde ABD Merkez Bankası'nın (FED) açıklamaları ve uluslararası finansal kuruluşlar tarafından Türkiye'nin yüksek döviz kuru ve cari açık nedeniyle kırılgan ülke olarak nitelendirilmesi, döviz kuru riskinden korunma konusunu önemli hale getirmiştir. $\mathrm{Bu}$ bakımdan vadeli işlem piyasasının gelişmesi, bankacılık sektörünün bu piyasada uzmanlaşması ve yoğunlaşması gerekmektedir. Bankacılık sektörünün 2001 yılı itibariyle vadeli işlem piyasasında daha çok spekülatif amaçlı yoğunlaştığı görülmektedir. Bankacılık sektörünün bu piyasada kur riskinden koruma amaçlı yoğunlaşması, maruz kaldığı risk ve belirsizlikleri en aza indirebilecek ve sektörün dayanıklılığını artırabilecektir.

Türk bankacılık sektöründeki yüksek yabacı para pozisyonları, yüksek kredi/mevduat oranı, yüksek fonlama maliyetleri ve bilançodaki vade uyumsuzluğu gibi döviz kuruna duyarlı işlemleri kısıtlayıcı düzenlemeler de kur şoklarının olumsuz etkisini azaltabilecektir. Diğer taraftan, bankalar kur riskinden korunma konusundaki deneyimlerini karşılıklı paylaşmak üzere teşvik edilmeleri yönünde bir politikası düzenlenmesi gerekmektedir. $\mathrm{Bu}$ sayede bankacılık sektörü döviz kuru risk yönetiminde daha etkin hale gelebilecektir.

Uluslararası Ödemeler Bankası tarafından risk yönetimi ile ilgili Basel III kapsamında düzenlenen uluslararası standartların ve kriterlerin benimsenmesi, Türk bankacılık sektörünün altyapısının daha sağlıklı hale gelebilmesi açısından uyum sürecinde önem taşımaktadır. Buna göre bir taraftan bankalar uluslararasılaşma sürecinde uluslararası standartlarla piyasada işlem yapabilecek, diğer taraftan ani dış şoklar ve olumsuz etkilerinden daha az etkileneceklerdir.

\section{Sonuç}

Bankacılık sektörü performansına ilişkin literatürdeki uygulamalı çalışmaların bulguları, performansın birçok farklı faktörden etkilendiğini ortaya koymuştur. Bunları bankaya özgü veya iç faktörler, piyasaya özgü ve makro ekonomik veya dış faktörler olarak sınıflandırmak mümkündür. Yapılan çalışmalar bankacılık sektörü performansı, özellikle de karlılık üzerinde bankaya özgü değişkenlerin daha etkili olduğu yönündedir. Bununla beraber iktisadi dengeleri hassas olan ekonomilerde, makro faktörlerin de en az bankaya özgü faktörler kadar performans üzerinde etkili olduğu şeklindedir. Türkiye gibi önemli yükselen piyasa ekonomileri hızlı bir büyüme süreci izlemektedir. Bununla beraber, böyle ülkelerin çoğunda ulusal tasarruf düzeyi büyüme sürecini desteklemeye yeterli olmamakta ve tasarruf açığı yabancı fonlarla karşılanmaktadır. Ancak, bu fonlar kısa vadeli ve spekülatif yapıda olduklarından döviz kuru şoklarına duyarlılık gibi bir sorun doğmaktadır.

Türkiye ekonomisi de bu yapıya büyük oranda uymaktadır. Hem bankacılık sistemindeki yabancı sermaye oranı hem de bankaların döviz yükümlülükleri oldukça yüksektir. Bankaların 
sendikasyon kredileri ve kısa vadeli döviz tevdiat hesapları gibi kısa vadeli döviz yükümlülükleri de bir hayli fazladır. Dolayısıyla, bankaların döviz kuru riskine duyarlılıkları yüksektir. Olası ani ve yüksek kur artışları ve/veya aşırı kur oynaklıkları, bankaların kaynak maliyetlerini hızla arttırarak önemli karlılık düşüşlerine, dönemsel zararlara, hatta açık pozisyonu yüksek bankalarda iflaslara neden olabilir. Bu değerlendirmelerden hareketle, çalışmamızda bankacılık sektörü performansı ile döviz kuru hareketleri arasındaki ilişki üzerinde durulmuştur.

ARDL modelleri kullanılarak, ABD Doları ve Euro kurlarının banka performans ölçütleri olan ROA, ROE ve NIM üzerindeki etkileri araştırılmıştır. Yapılan eş bütünleşme testleri ile bu değişkenler arasında uzun dönemli bir ilişki olup olmadığı analiz edilmiştir. Analiz bulgularına göre, bazı modellerde eş bütünleşme ilişkileri saptansa da Türkiye'de faaliyet gösteren bankaların karlılık performansının döviz kuru hareketlerinden etkilenmediğini göstermektedir. Bu sonuçlar öngörülenin aksine, Türk bankacılık sisteminin kur şoklarına karşı dayanıklı olduğu şeklinde yorumlanabilir. Bununla beraber, daha kesin değerlendirmelerde bulunulabilmesi için kapsamlı veri kümeleri ve alternatif analiz yöntemleriyle yeni uygulamaların yapılması gerekmektedir.

Türkiye'de döviz kuru riskinin en aza indirebilmesi için birçok yöntem bulunmaktadır. $\mathrm{Bu}$ yöntemlerin birçoğu vadeli işlem piyasasında yer almaktadır. Dolayısıyla, vadeli işlem piyasasının gelişmesi bankacılık sektörünün döviz kuru riskine karşı dayanıklı hale gelmesi açısından önem taşımaktadır. Bu amaçla; döviz kuru riskine duyarlı işlemleri kısıtlayıcı düzenlemeler, bankaların bu konudaki deneyimlerini paylaşmayı teşvik eden politikalar ve uluslararası standartlar ile kriterlere tam uyum sağlayarak sektörün altyapısının güçlendirilmesi gerekmektedir.

Hakem Değerlendirmesi: Dış bağımsız.

Çıkar Çatışması: Yazar çıkar çatışması bildirmemiştir.

Finansal Destek: Yazar bu çalışma için finansal destek almadığını beyan etmiştir.

Peer-review: Externally peer-reviewed.

Conflict of Interest: The author has no conflict of interest to declare.

Grant Support: The author declared that this study has received no financial support.

\section{Kaynakça}

Almazari, A. A. (2013). Capital adequacy, cost income ratio and the performance of Saudi banks. International Journal of Academic Research in Accounting, Finance and Management Sciences, 3(4), 284-293.

Athanasoglou, P. P., Delis Matthaios, D., Staikouras Christos, K. (2006). Determinants of bank profitability in the South Eastern European Region, MPRA Paper No. 10274. 
Bleaney, M., Bougheas, S., \& Skamnelos, I. (2008). A model of the interactions between banking crises and currency crises. Journal of International Money and Finance, 27(5), 695-706.

Bracker, K., Imhof, M., \& Lallemand, J. (2009). Sources of bank risks: impacts and explanations. Academy of Banking Studies Journal, 8(2), 107-124.

Buch, C. M., \& Heinrich, R. P. (1999). Twin crises and the intermediary role of banks. International Journal of Finance \& Economics, 4(4), 313-323.

Chamberlain, S., Howe, J. S., \& Popper, H. (1997). The exchange rate exposure of US and Japanese banking institutions. Journal of banking \& finance, 21(6), 871-892.

Christian, C., Moffitt, J. S., \& Suberly, L. A. (2008). Fundamental analysis for evaluating bank performance: what variables provide the greatest insight into future earnings?. Bank Accounting \& Finance, 21(6), 17-25.

Demirgüç-Knut, A., \& Huizinga H. (1999). Financial structure and bank profitability, World Bank Policy Research Working Paper, No: 2430.

Flamini, V., Calvin, M., \& Liliana, S. (2009). The determinants of commercial bank profitability in Sub-Saharan Africa. International Monetary Fund Working Paper.

Gilbert, R. A., \& Wheelock, D. C. (2007). Measuring commercial bank profitability: Proceed with caution. Federal Reserve Bank of St. Louis Review, 89(6), 515-532.

Goddard, J., Molyneux, P., \& Wilson, J. O. (2004). The profitability of European banks: a cross-sectional and dynamic panel analysis. The Manchester School, 72(3), 363-381.

Gökçe, A., \& Sarıtaş, H., (2017), Döviz kurlarındaki değişimlerin Türkiye'deki özel sermayeli bankaların bilançoları üzerine etkileri, Pamukkale Üniversitesi Sosyal Bilimler Enstitüsü Dergisi, 28.

He. Ling T., Fyaman, A., \& Casey K. M. (2014). Bank profitability: The impact of foreign currency fluctuations, Journal of Applied Business and Economics, 16(2), 98-104.

Kaya, H., (2018). 2001 Kriz sonrası Türkiye'de döviz kuru ve enflasyon ilişkisi: döviz kuru geçiş etkisinin VAR analizi, Ankara Üniversitesi SBF Dergisi, 73(3), 841-865.

Kılıcı, E. N. (2019). Türkiye makro finansal görünümüne ilişkin bir değerlendirme ve reel kur-geri dönmeyen krediler ilişkisine yönelik bir analiz. Siyaset, Ekonomi ve Yönetim Araştırmalar Dergisi, 7 (3), 23-37.

Maudos, J., \& Fernandez, D. G. J. (2004). Factors explaining the interest margin in the banking sectors of European Union. Journal of Banking and Finance, 28, 2259-2281.

Nouaili, M, Abaoub, E, \& Ochi, A. (2015). The determinants of banking performance in front of financial changes: Case of trade banks in Tunisia. International Journaş of Economics and Financial Issues, 5(2), 410-417.

Osuagwo, E. S. (2014). Determinants of bank profitability in Nigeria, International Journal of Economics and Finance, 6(12), 45-63.

Pesaran, M. H., Shin, Y., \& Smith, R. J. (2001). Bounds testing approaches to the analysis of level relationships. Journal of Applied econometrics, 16(3), 289-326.

Samadi, M. (2012). An empirical study on the impact of operating risk on structure capital and profitability in Iranian banking sector. Management Science Letters, 2(5), 1689-1694.

Saunders, A., \& Schumacher, L. (2000). The determinants of bank interest rate margins: an international study. Journal of International Money and Finance, 19(6), 813-832.

Shamki, D., Alulis, I. K., \& Sayari, K. (2016). Financial Information Influencing Commercial Banks Profitability. International Journal of Economics and Finance, 8(6), 166-174.

Short, B. K. (1979). The relation between commercial bank profit rates and banking concentration in Canada, Western Europe, and Japan. Journal of banking \& Finance, 3(3), 209-219.

Smirlock, M. (1985). Evidence on the (non) relationship between concentration and profitability in banking. Journal of Money, Credit and Banking, 17(1), 69-83. 
Wong, H., Wong, T., \& Leung, F. (2008). The foreign exchange exposure of Chinese banks. Journal of Finance and Economics, 12(3), 123-134.

Zeyneloğlu, İ. (2017). Banka Davranışları ve Döviz Kuru. Finans Politik \& Ekonomik Yorumlar, 54(634), 27-39.

BDDK. (2010). Krizde istikrara Türkiye tecrübesi, Erişim adresi: https://www.bddk.org.tr/ContentBddk/dokuman/ duyuru_0395_02.pdf.

BDDK. (2019). Erişim adresi: https://www.bddk.org.tr/BultenAylik.

TCMB. (2019). Erişim adresi: https://evds2.tcmb.gov.tr/. 
